\title{
Alterations in expression of endometrial milk fat globule-EGF factor 8 (MFG-E8) and leukemia inhibitory factor (LIF) in patients with infertility and endometriosis
}

Carla Regina Schmitz ${ }^{1}$, Sergio Oehninger², Vanessa Krebs Genro³, Neelima Chandra², Frank Lattanzio ${ }^{4}$, Liang $\mathrm{Yu}^{2}$, João Sabino Cunha-Filho ${ }^{1,3}$

${ }^{1}$ Graduate Program in Internal Medicine of the Universidade Federal do Rio Grande do Sul, Porto Alegre, RS, Brazil

2Department of Obstetrics and Gynecology, Eastern Virginia Medical School, The Jones Institute for Reproductive Medicine, Norfolk VA, USA

${ }^{3}$ Department of Obstetrics and Gynecology, Universidade Federal do Rio Grande do Sul, Porto Alegre, RS, Brazil ${ }^{4}$ Department of Physiological Sciences, Eastern Virginia Medical School, Norfolk VA, USA

\begin{abstract}
Objective: The aim of this study was to compare the endometrial expression of milk fat globule-EGF factor 8 (MFG-E8), its receptor integrin $\operatorname{av} \beta 3$, and leukemia inhibitory factor (LIF) in patients with endometriosis and infertility and in healthy fertile patients during the window of implantation.

Methods: Five patients with peritoneal endometriosis and infertility (case group) and four healthy fertile patients (control group) were recruited. All patients were either diagnosed with or ruled out for endometriosis by laparoscopic surgery; the case group underwent surgery for infertility investigation and the control group for tubal ligation. Endometrial biopsies were performed in all patients during the window of implantation ( $\mathrm{LH}+8$ to $\mathrm{LH}+10$ ), and then the samples were analyzed by immunochemistry for MFG-E8, integrin av $\beta 3$, and LIF.

Results: In patients with endometriosis and infertility, expression of MFG-E8 was significantly increased in the glandular epithelium when compared to healthy fertile patients $(p<0.001)$. Moreover, LIF expression was lower in patients with endometriosis and infertility $(p<0.05)$. Nevertheless, we found no difference in integrin av $\beta 3$ expression between the groups $(p=0.084)$.

Conclusion: This study showed for the first time that MFG-E8 expression is impaired in the endometrium of patients with endometriosis and infertility during the window of implantation. Moreover, LIF is also diminished in the endometrium of these patients as shown before.
\end{abstract}

Keywords: MFG-E8, integrin $\operatorname{av} \beta 3$, LIF, human endometrium, endometriosis

\section{INTRODUCTION}

Endometriosis is one of the most common gynecologic diseases, and its clinical manifestations include dyspareunia, dysmenorrhea, chronic pelvic pain, and infertility (Howard, 2009; ASRM, 2006). It is present in approximately $10 \%$ of women in fertile age (Härkki et al., 2010), but among infertile patients, endometriosis prevalence can be as high as $25-50 \%$ (Dong et al., 2013). Although it is known for decades that endometriosis is associated with infertility, the pathogenesis of this association is still not completely understood (Härkki et al., 2010). Nevertheless, several studies have shown that endometriosis is associated with abnormal folliculogenesis, luteal insufficiency (Cunha-Filho et al., 2003; 2001), and abnormal embryo fertilization and implantation (Fadhlaoui et al., 2014), which contribute to infertility. Regarding lower implantation rates, it has been shown that some endometrial receptivity markers may be impaired in the endometrium of these patients (Lu et al., 2013; Dimitriadis et al., 2006; Dong et al., 2013).

Leukemia inhibitory factor (LIF) and integrin $\operatorname{av} \beta 3$ are well-known endometrial receptivity markers. LIF is a polyfunctional pleiotropic cytokine, which belongs to the IL-6 family (Tawfeek et al., 2012). Stewart et al. (1992) have shown for the first time that mice lacking a functional LIF gene fail to implant blastocysts in their endometrium. Since then, many authors have demonstrated that proper LIF expression by the endometrium is also important for female fertility (Lalitkumar et al., 2013; Mikolajczyk et al., 2007). LIF is expressed mainly in the glandular and luminal epithelium of the endometrium during the window of implantation (Vogiagis et al., 1996). Impaired LIF expression has been shown in patients with unexplained infertility, uterine anatomical abnormalities, and endometriosis (Mikolajczyk et al., 2007; Hasegawa et al., 2012; Dimitriadis et al., 2006).

Integrin av $\beta 3$ is a transmembrane glycoprotein that has been extensively studied in the human endometrium. It can be detected in the epithelial layer of mice and the human endometrium during the window of implantation (Apparao et al., 2001; Liu et al., 2013; Franchi et al., 2011). Several studies have demonstrated that decreased expression of this protein can impair embryo implantation in vitro (Zhang et al., 2011; Kaneko et al., 2011; Kang et al., 2014; Schmitz et al., 2014). Moreover, patients with hydrosalpinx, unexplained infertility and recurrent pregnancy loss have presented impaired integrin av $\beta 3$ expression (Daftary et al., 2007; Tei et al., 2003; Germeyer et al., 2014). Nevertheless, the relationship between this integrin and endometriosis has been controversial in the literature (Lessey et al., 1994; Ordi et al., 2003; Casals et al., 2012).

Milk fat globule epidermal growth factor 8 (MFG-E8) is a novel protein recently associated to the implantation process (Mirkin et al., 2005). Franchi et al. (2011) demonstrated for the first time that MFG-E8 is expressed in the human endometrial epithelium and that it is up-regulated during the window of implantation. Besides, MFG-E8 histological sequence in epithelial cell location suggests luminal secretion of the protein (Franchi et al., 2011). Moreover, we have demonstrated that blocking this protein in an in vitro trophoblast/endometrial epithelium model can impair the implantation process (Schmitz et al., 2014). Nevertheless, this protein has never been studied in the endometrium of infertile patients.

Ultimately, what constitutes adequate expression of endometrial receptivity markers integrin av $\beta 3$ and LIF is still controversial in endometriosis patients, while MFG-E8 has not yet been studied in these patients. Considering that endometriosis patients may have an impaired 
implantation process, this study aimed to compare the endometrial expression of MFG-E8, integrin av $\beta 3$, and LIF between patients with infertility and endometriosis and healthy fertile patients (controls) during the window of implantation.

\section{MATERIALS AND METHODS}

\section{Design}

This prospective case-control study was carried out in the Department of Gynecology of the Hospital de Clínicas de Porto Alegre and in the Jones Institute for Reproductive Medicine. The STROBE guideline was used (von Elm et al., 2007).

\section{Subjects}

Five patients with peritoneal endometriosis and infertility (case group) and four healthy fertile patients (control group) were recruited between January 2014 and November 2014 to take part in the study. Diagnosis of infertility was considered when the couple had not conceived after 12 months of contraceptive-free intercourse (ASRM, 2008). The case group included consecutive patients diagnosed with peritoneal endometriosis during laparoscopic surgery meeting the enrollment criteria described below. The degree of endometriosis was categorized based on to the revised classification of endometriosis of the American Society for Reproductive Medicine (ASRM, 1997). Patients submitted to elective laparoscopic tubal ligation were invited to join the control group. These individuals were ruled out for endometriosis (by laparoscopy), had a history of normal fertility, and were non-smokers.

The individuals in the case and control groups had to meet the following enrollment criteria: (i) age between 25 and 38 years (ii) regular menstrual cycles, (iii) presence of both ovaries, (iv) no endocrine disorder and (v) no family history of genetic disease. The case group also had normal sperm analysis. Patients with abnormal ovarian reserve (antral follicle count under 10$)$, obesity (BMI $\geq 30$ ), history of miscarriage, and smokers were excluded.

The local ethics committee approved this study and a written informed consent was provided to all subjects prior to sample collection (IRB equivalent).

\section{Endometrial samples}

Endometrial biopsies were performed during the natural cycle during the putative window of implantation $(\mathrm{LH}+8$ to $\mathrm{LH}+10)$. $\mathrm{LH}+1$ was considered the day of ovulation (Kao et al., 2003). Ovulation was detected by serial ultrasound exams, and it was defined as the 24-h period that separated the identification of a mature, preovulatory follicle on one scan and either of the following on the next scan: (i) follicle rupture; (ii) presence of an early corpus luteum; (iii) presence of free fluid in the cul-de-sac (Ecochard et al., 2013).

The biopsies were performed with a Pipelle ${ }^{\circledR}$ catheter ( $C C D$, Paris, France). Each endometrial biopsy specimen was fixed in formalin and embedded in paraffin in preparation for histological examination and detection of MFG-E8, integrin av $\beta 3$, and LIF by immunostaining.

\section{Immunohistochemistry}

Paraffin-embedded tissue blocks of the endometrial biopsy specimens were cut into $5-\mu \mathrm{m}$ sections. Immunohistochemistry was performed as previously described (Chandra et al., 2013). Briefly, the slides were deparaffinized, dehydrated, and rehydrated followed by immersion in retrieval solution 1:10 (Dako). Endogenous peroxidases were quenched with $3 \%$ hydrogen peroxide for $10 \mathrm{~min}$ and non-specific binding sites were blocked with $1.5 \%$ normal goat or horse serum (Vector Laboratories) for $30 \mathrm{~min}$ at room temperature. The sections were then covered by appropriate dilutions of primary antibody, MFG-E8 (Abcam) 1:100, integrin av 33 (Santa Cruz Biotechnologies) $1: 10$ or LIF (Sigma) 1:750, and placed in a refrigerator overnight. After primary antibody incubation, the sections were washed with PBS and incubated with anti-mouse or anti-rabbit secondary antibody (Vector Lab) at a dilution of $1: 200$ for $30 \mathrm{~min}$ at room temperature. After incubation with secondary antibodies, the tissues were incubated with $A B C$ reagent (Vector Laboratories) for 30 min, followed by PBS wash. The antigens were localized by incubation with AEC chromogen-substrate (skyTek Labs) and finally mounted with Accergyl mounting media (Accurate Chemicals) with a cover slip. Negative controls included sections treated with a similar dilution of a nonimmune IgG1 (isotype control, eBioscience, San Diego, CA, USA). Representative images were photographed with an Olympus BX50 microscope using an Olympus DP70 Q-color 3 camera (Franchi et al., 2011).

The assessment of staining intensity and distribution for integrin and LIF was made using the semi-quantitative histologic score (HSCORE) system. The HSCORE was calculated using the following equation: HSCORE: $\Sigma$ Pi $(i+$ 1 ), where i represents the intensity of staining on a scale from 1 to 3 ( 1 for weak, 2 for moderate, and 3 for strong staining) and $\mathrm{Pi}$ the percentage of stained endometrial stromal and epithelial cells for each intensity, varying from 0-100\%, as previously described (Lessey et al., 2006).

The assessment for staining intensity and distribution for MFG-E8 was made using computerized image analysis using a modification of Fuhrich et al. (2013), with the aid of Metamorph $^{\mathrm{TM}}$ (Molecular Devices) instead of software program Image $\mathrm{J}$. The original method was found to be highly correlated with HSCORE values obtained by expert evaluators. Color images collected using an Olympus 20x objective were automatically thresholded rather than manually circumscribed, and the thresholded areas from three different 20x fields were averaged and subtracted from total white (255) values on an eight byte scale, as published earlier (Fuhrich et al., 2013). A size filter setting was used to exclude stray pixels so that only cell structures were analyzed.

\section{Statistical analysis}

The statistical analysis was carried out using software package SPSS 18.0. The measure of central tendency used was the mean and the measure of variability was the standard deviation (Lambalk et al., 2004). Categorical variables in the two groups were compared using the 2-sided Pearson Chi-squared test. Continuous variables were compared using Student's t-test. Differences with a $p$-value $<5 \%$ were considered significant.

\section{RESULTS}

Five patients with endometriosis and infertility were included in the case group and four healthy fertile patients were enrolled in the control group. Table 1 shows patient demographic characteristics. In the case group, four patients had stage I endometriosis and one had stage II endometriosis.

Immunohistochemistry confirmed previous findings and revealed that MFG-E8 was predominantly located in glandular epithelium. MFG-E8's receptor, integrin avß3, was localized in the epithelial, as well as in the stromal layer. Immunolocalization showed that LIF was preferentially observed in the luminal epithelium (Figure 1).

Figure 2 shows the mean HSCORE for MFG-E8, integrin $\operatorname{av} \beta 3$ and LIF. Statistically significant differences were found for MFG-E8 $(p<0.001)$ and LIF $(p=0.033)$ between the control and case groups. No significant difference was found for integrin $\operatorname{av} \beta 3(p=0.084)$. 
Table 1. Demographic characteristics of women with infertility and endometriosis (case group) and healthy fertile women (control group).

\begin{tabular}{|l|c|c|c|}
\hline & Control group (n=4) & Case group (n=5) & p value \\
\hline Age (years) & $35.2 \pm 2.2$ & $30.4 \pm 4.3$ & $.084^{\mathrm{a}}$ \\
\hline $\begin{array}{l}\text { Race Caucasian } \\
\text { African-Brazilian }\end{array}$ & $3(75 \%)$ & $4(80 \%)$ & $0.86^{\mathrm{b}}$ \\
\hline BMI $\left(\mathrm{Kg} / \mathrm{m}^{2}\right)$ & $1(25 \%)$ & $1(20 \%)$ & $.156^{\mathrm{a}}$ \\
\hline Menarche (years) & $26.6 \pm 2.8$ & $22.8 \pm 4.1$ & $.216^{\mathrm{a}}$ \\
\hline AFC & $11.5 \pm 1.3$ & $12.6 \pm 1.1$ & $.727^{\mathrm{a}}$ \\
\hline
\end{tabular}

All values are means $\pm S D$;

$\mathrm{BMI}=$ body mass index;

$\mathrm{AFC}=$ antral follicle count;

a Student's t-test;

b Chi-squared test.

\section{DISCUSSION}

This study showed for the first time that patients with endometriosis and infertility have increased MFG-E8 expression in the endometrium during the putative window of implantation. Patients also had decreased LIF expression during the same period. Nevertheless, no differences were found in the expression of integrin $\operatorname{av} \beta 3$ between the groups.

MFG-E8 is a glycoprotein identified for the first time in 1990 (Stubbs et al., 1990). Since then, it has been extensively studied in many physiological and pathological processes, especially in the immune system (Matsuda et al., 2011; Oba et al., 2011). A possible role for MFG-E8 in the implantation process was pointed out for the first time in 2005, when it was found up-regulated during the window of implantation (Mirkin et al., 2005). After that, other studies suggested its participation in the implantation process (Franchi et al., 2011; Schmitz et al., 2014); however, to the best of our knowledge, it had never been studied in the endometrium of infertile patients.

MFG-E8 is known to be involved in inflammatory processes (Komura et al., 2009), and it is regulated by TNF-a in the human endometrium (Yu et al., 2014). Moreover, endometriosis patients are known to present chronic inflammation (Zhao et al., 2015a; Berkes et al., 2014). Therefore, our hypothesis that endometriotic/ infertile patients have increased MFG-E8 expression during the window of implantation was confirmed in the current study. We had previously shown in an in-vitro model that blocking MFG-E8 impairs the implantation process (Schmitz et al., 2014). Nevertheless, it seems that either the down regulation (Sinningen et al., 2015) or the up-regulation of MFG-E8 may impair physiological processes (Zhao et al., 2015b; Yamamoto et al., 2014).

MFG-E8 receptor integrin av $\beta 3$ is a well-established endometrial receptivity marker. Nevertheless, its expression in the endometrium of individuals with endometriosis has been a topic of controversy in the literature. Our study found no differences in the expression of integrin av $\beta 3$ between the groups, although levels tended to be lower in the case group $(p=0.084)$. In 1994, a large study with 241 individuals with endometriosis showed that subjects with stage I/II endometriosis had decreased integrin expression (Lessey et al., 1994). However, the authors included biopsies after day 19 of the cycle, and not only during the window of implantation. Moreover, the study did not mention if all patients were infertile. On the other hand, two smaller studies failed to find such difference (Ordi et al., 2003; Casals et al., 2012) after analyzing integrin av $\beta 3$ expression during the window of implantation.
A possible cause for the decrease in integrin av $\beta 3$ expression is the fact that these patients had impaired HOXA10 production, which is responsible for the expression of subunit $\beta 3$ (Taylor et al., 1999; Lu et al., 2013; Zhu et al., 2013). The overexpression of MFG-E8 may also down regulate the production of its receptor.

Another important endometrial receptivity marker that seems to be impaired in the endometrium of individuals with endometriosis is LIF. As also seen in our results, Dimitriadis et al. (2006) previously described diminished expression of LIF in patients with stage I/II endometriosis during the window of implantation. In addition, Alizadeh et al. (2011) also reported impaired LIF expression in a similar group of patients. Nevertheless, a study with 14 endometriosis patients showed no difference in LIF levels in uterine flushings when compared to fertile controls (21 patients) (Mikolajczyk et al., 2007).

The method used in this study is a modification of a previously published technique (Fuhrich et al., 2013) that allows for faster and more accurate results; the thresholding function in Metamorph ${ }^{\mathrm{TM}}$ removes holes in background objects, thus allowing the quantification of thresholded areas only. Manually circumscribing objects as in Fuhrich et al., 2013 is much slower and may also include holes, which reduces the averaged staining intensity in a variable fashion depending on the individual object's hole area. Size filter settings in Metamorph ${ }^{\mathrm{TM}}$ were also used to exclude stray pixels and small debris, enabling a more accurate measurement of cell structures. Unfortunately, not all types of staining can be adequately analyzed by this method, as integrin and LIF. This is why the traditional $\mathrm{H}$-score was used in this study.

Although it may be argued that the study sample was relatively small, statistical significant differences were found. Moreover, the results agreed with what we were expecting, based on biological plausibility. Although we did not measure serum or urinary LH levels to further define the ovulation day, previous studies have defined ovulation only with ultrasound (Ecochard et al., 2013).

In conclusion, our study showed for the first time that patients with endometriosis and infertility have altered MFG-E8 expression in the endometrium during the putative window of implantation. Moreover, we also demonstrated that these patients have diminished LIF, as shown before. Nevertheless, there was no difference in the expression of integrin av $\beta 3$, although in the case group levels tended to be lower. The endometrium of patients with endometriosis must be more thoroughly characterized to improve the understanding of the association between this condition and infertility. 

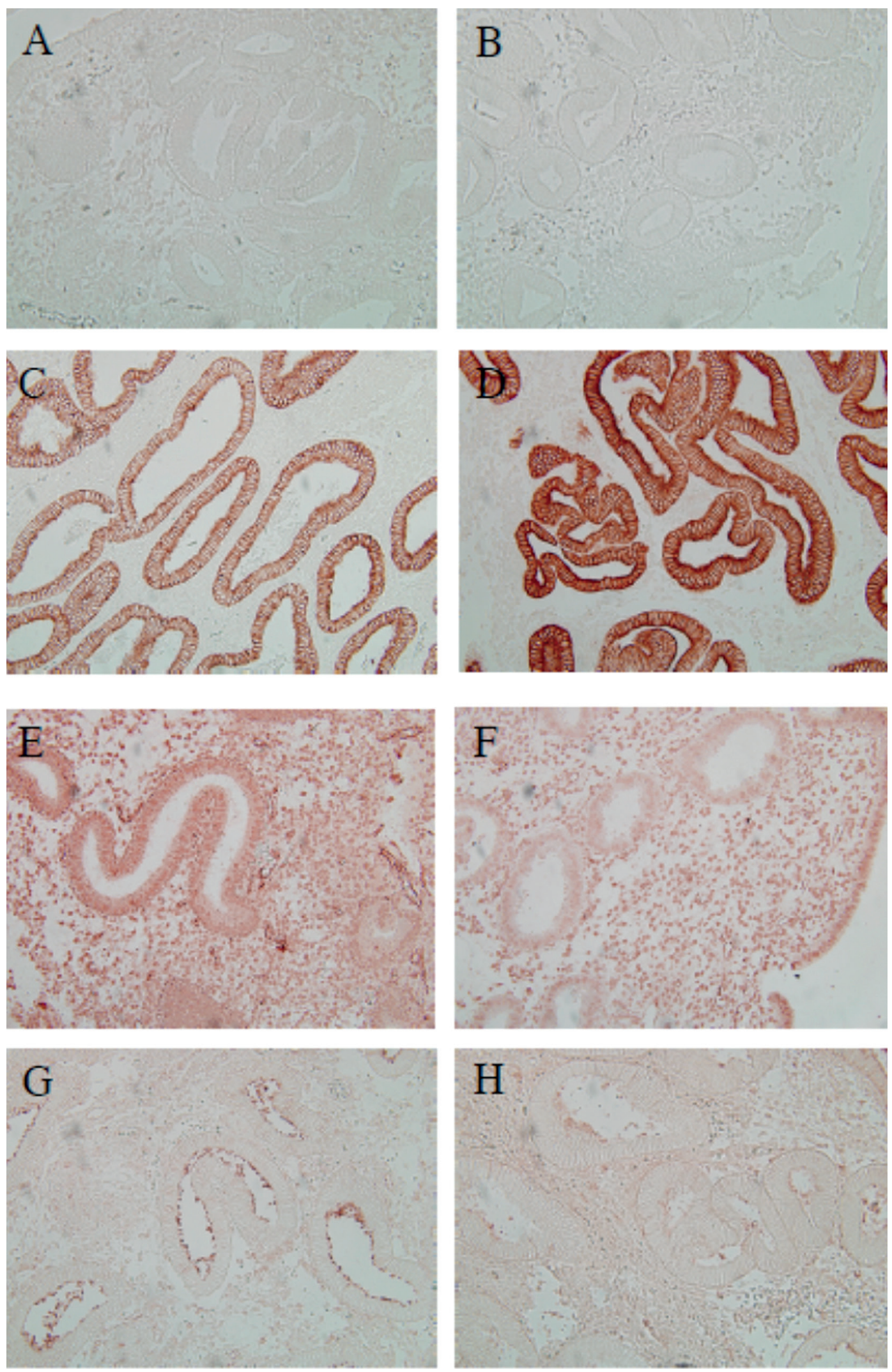

Figure 1. Immunohistochemical localization of MFG-E8, integrin av $\beta 3$, and LIF in the human endometrium. Representative images of: (A) negative control from the control group (endometriosis and infertility), (B) and from the case group (healthy fertile patients); (C) MFG-E8 staining from the control group, (D) and from the case group; (E) Integrin av $\beta 3$ staining from the control group, (F) and from the case group; and (G) LIF staining from the control group and from the case group (H). 

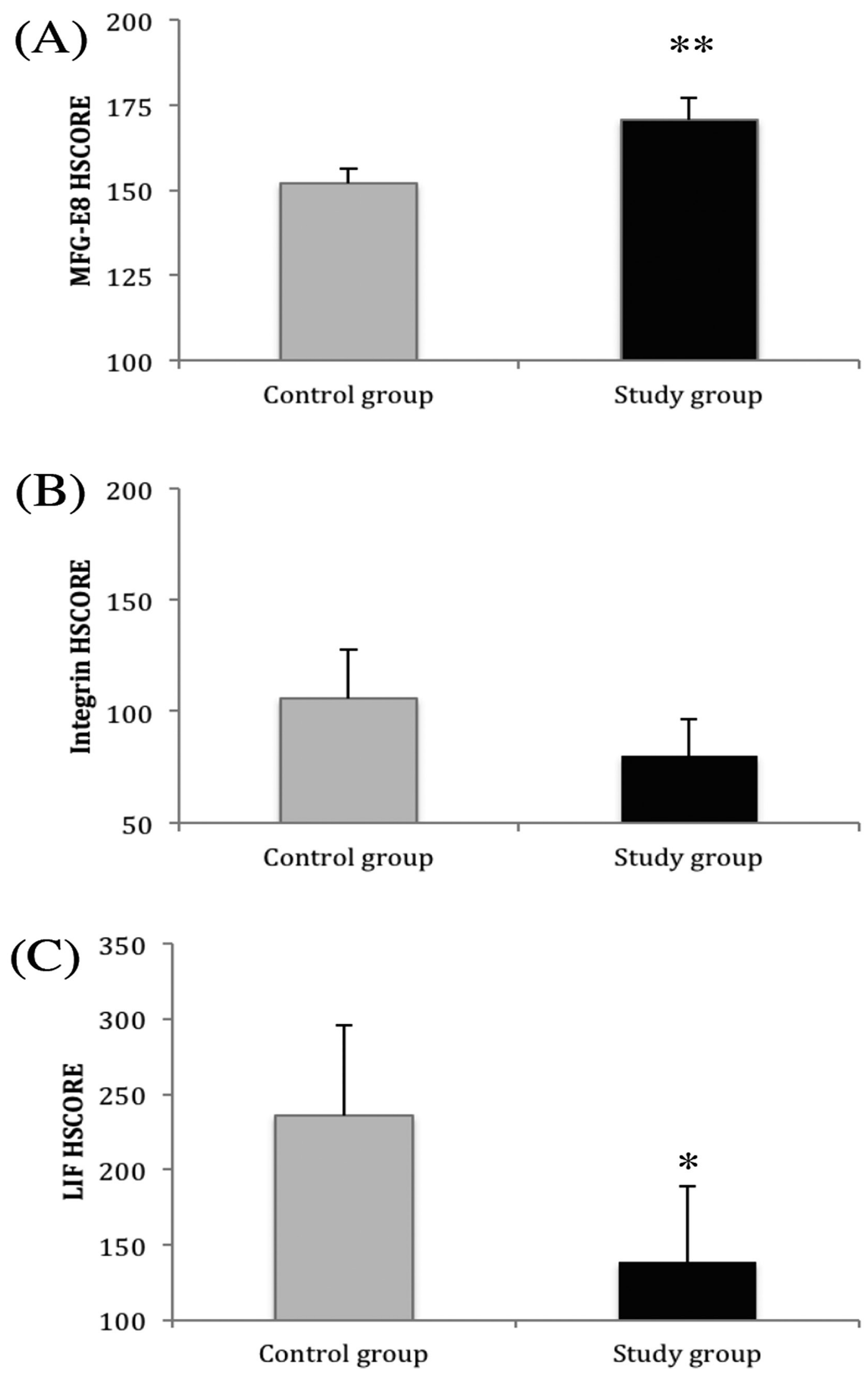

Figure 2. MFG-E8 (A), integrin av $\beta 3$ (B) and LIF (C) HSCORE in healthy fertile patients (control group) and in patients with endometriosis and infertility. ${ }^{* *} p<0.001$ compared with controls. ${ }^{*} p<0.05$ compared with controls. 


\section{ACKNOWLEDGMENTS}

This study was supported by grants from the CNPq (Conselho Nacional de Desenvolvimento Científico e Tecnológico) and from the Fundo de Incentivo a Pesquisa (FIPE) of Hospital de Clínicas de Porto Alegre, RS - Brazil.

\section{CONFLICT OF INTEREST}

The authors have no conflicts of interest to declare.

\section{Corresponding author:}

Carla Regina Schmitz

Hospital de Clínicas de Porto Alegre

Departamento de Ginecologia e Obstetrícia,

Porto Alegre, RS, Brazil.

E-mail address: crschmitz@gmail.com.

\section{REFERENCES}

Alizadeh Z, Shokrzadeh N, Saidijam M, Sanoee MF. Semiquantitative analysis of HOXA11, leukemia inhibitory factor and basic transcriptional element binding protein 1 mRNA expression in the mid-secretory endometrium of patients with endometriosis. Iran Biomed J. 2011;15:66-72. PMID: 21987111

Apparao KB, Murray MJ, Fritz MA, Meyer WR, Chambers $A F$, Truong PR, Lessey BA. Osteopontin and its receptor alphavbeta(3) integrin are coexpressed in the human endometrium during the menstrual cycle but regulated differentially. J Clin Endocrinol Metab. 2001;86:49915000. PMID: 11600576 DOI: 10.1210/jcem.86.10.7906

ASRM. American Society for Reproductive Medicine. Revised American Society for Reproductive Medicine classification of endometriosis: 1996. Fertil Steril. 1997;67:817-21. PMID: 9130884 DOI: 10.1016/S0015-0282(97)81391-X

ASRM. Practice Committee of the American Society for Reproductive Medicine. Endometriosis and infertility. Fertil Steril. 2006;86:S156-60. PMID: 17055813 DOI: 10.1016/j.fertnstert.2006.08.014

ASRM. Practice Committee of the American Society for Reproductive Medicine. Definitions of infertility and recurrent pregnancy loss. Fertil Steril. 2008;90:S60. PMID: 19007647 DOI: 10.1016/j.fertnstert.2008.08.065

Berkes E, Oehmke F, Tinneberg HR, Preissner KT, Saffarzadeh M. Association of neutrophil extracellular traps with endometriosis-related chronic inflammation. Eur J Obstet Gynecol Reprod Biol. 2014;183:193-200. PMID: 25461378 DOI: $10.1016 /$ j.ejogrb.2014.10.040

Casals G, Ordi J, Creus M, Fábregues F, Carmona F, Casamitjana R, Balasch J. Expression pattern of osteopontin and $\operatorname{av} \beta 3$ integrin during the implantation window in infertile patients with early stages of endometriosis. Hum Reprod. 2012;27:805-13. PMID: 22215628 DOI: $10.1093 /$ humrep/der432

Chandra N, Thurman AR, Anderson S, Cunningham TD, Yousefieh N, Mauck C, Doncel GF. Depot medroxyprogesterone acetate increases immune cell numbers and activation markers in human vaginal mucosal tissues. AIDS Res Hum Retroviruses. 2013;29:592-601. PMID: 23189932 DOI: 10.1089/aid.2012.0271
Cunha-Filho JS, Gross JL, Bastos de Souza CA, Lemos NA, Giugliani C, Freitas F, Passos EP. Physiopathological aspects of corpus luteum defect in infertile patients with mild/minimal endometriosis. J Assist Reprod Genet. 2003;20:117-21. PMID: 12735387 DOI: 10.1023/A: 1022625106489

Cunha-Filho JS, Gross JL, Lemos NA, Brandelli A, Castillos $M$, Passos EP. Hyperprolactinemia and luteal insufficiency in infertile patients with mild and minimal endometriosis. Horm Metab Res. 2001;33:216-20. PMID: 11383925 DOI: $10.1055 / \mathrm{s}-2001-14945$

Daftary GS, Kayisli U, Seli E, Bukulmez O, Arici A, Taylor HS. Salpingectomy increases peri-implantation endometrial HOXA10 expression in women with hydrosalpinx. Fertil Steril. 2007;87:367-72. PMID: 17173899 DOI: 10.1016/j. fertnstert.2006.06.041

Dimitriadis E, Stoikos C, Stafford-Bell M, Clark I, Paiva P, Kovacs G, Salamonsen LA. Interleukin-11, IL11 receptoralpha and leukemia inhibitory factor are dysregulated in endometrium of infertile women with endometriosis during the implantation window. J Reprod Immunol. 2006;69:53-64. PMID: 16310857 DOI: 10.1016/j.jri.2005.07.004

Dong $X$, Liao $X$, Wang $R$, Zhang $H$. The impact of endometriosis on IVF/ICSI outcomes. Int J Clin Exp Pathol. 2013;6:1911-8. PMID: 24040458

Ecochard R, Leiva R, Bouchard $T$, Boehringer $H$, Direito $A$, Mariani A, Fehring R. Use of urinary pregnanediol 3-glucuronide to confirm ovulation. Steroids. 2013;78:103540. PMID: 23831784 DOI: 10.1016/j.steroids.2013.06.006

Fadhlaoui A, Bouquet de la Jolinière J, Feki A. Endometriosis and infertility: how and when to treat? Front Surg. 2014;1:24. PMID: 25593948 DOI: 10.3389/fsurg.2014.00024

Franchi A, Bocca S, Anderson S, Riggs R, Oehninger S. Expression of milk fat globule EGF-factor 8 (MFG-E8) mRNA and protein in the human endometrium and its regulation by prolactin. Mol Hum Reprod. 2011;17:360-71. PMID: 21177637 DOI: 10.1093/molehr/gaq102

Fuhrich DG, Lessey BA, Savaris RF. Comparison of HSCORE assessment of endometrial beta3 integrin subunit expression with digital HSCORE using computerized image analysis (ImageJ). Anal Quant Cytopathol Histpathol. 2013;35:210-6. PMID: 24341124

Germeyer A, Savaris RF, Jauckus J, Lessey B. Endometrial beta3 Integrin profile reflects endometrial receptivity defects in women with unexplained recurrent pregnancy loss. Reprod Biol Endocrinol. 2014;12:53. PMID: 24950982 DOI: $10.1186 / 1477-7827-12-53$

Härkki P, Tiitinen A, Ylikorkala O. Endometriosis and assisted reproduction techniques. Ann $N$ Y Acad Sci. 2010;1205:207-13. PMID: 20840274 DOI:

10.1111/j.1749-6632.2010.05656.x

Hasegawa $E$, Ito $H$, Hasegawa $F$, Hatano K, Kazuka M, Usuda S, Isaka K. Expression of leukemia inhibitory factor in the endometrium in abnormal uterine cavities during the implantation window. Fertil Steril. 2012;97:953-8. PMID: 22341639 DOI: $10.1016 /$ j.fertnstert.2012.01.113 
Howard FM. Endometriosis and mechanisms of pelvic pain. J Minim Invasive Gynecol. 2009;16:540-50. PMID: 19835795 DOI: 10.1016/j.jmig.2009.06.017

Kaneko $Y$, Day ML, Murphy CR. Integrin $\beta 3$ in rat blastocysts and epithelial cells is essential for implantation in vitro: studies with Ishikawa cells and small interfering RNA transfection. Hum Reprod. 2011;26:1665-74. PMID: 21531996 DOI: 10.1093/humrep/der128

Kang YJ, Forbes K, Carver J, Aplin JD. The role of the osteopontin-integrin av $\beta 3$ interaction at implantation: functional analysis using three different in vitro models. Hum Reprod. 2014;29:739-49. PMID: 24442579 DOI: $10.1093 /$ humrep/det433

Kao LC, Germeyer A, Tulac S, Lobo S, Yang JP, Taylor RN, Osteen K, Lessey BA, Giudice LC. Expression profiling of endometrium from women with endometriosis reveals candidate genes for disease-based implantation failure and infertility. Endocrinology. 2003;144:2870-81. PMID: 12810542 DOI: $10.1210 /$ en.2003-0043

Komura $H$, Miksa M, Wu R, Goyert SM, Wang P. Milk fat globule epidermal growth factor-factor VIII is downregulated in sepsis via the lipopolysaccharide-CD14 pathway. J Immunol. 2009;182:581-7. PMID: 19109191 DOI: $10.4049 /$ jimmunol.182.1.581

Lalitkumar S, Boggavarapu NR, Menezes J, Dimitriadis E, Zhang JG, Nicola NA, Gemzell-Danielsson K, Lalitkumar LP. Polyethylene glycated leukemia inhibitory factor antagonist inhibits human blastocyst implantation and triggers apoptosis by down-regulating embryonic AKT. Fertil Steril. 2013;100:1160-9. PMID: 23876532 DOI: 10.1016/j.fertnstert.2013.06.023

Lambalk CB, de Koning $\mathrm{CH}$, Flett A, Van Kasteren Y, Gosden $\mathrm{R}$, Homburg R. Assessment of ovarian reserve. Ovarian biopsy is not a valid method for the prediction of ovarian reserve. Hum Reprod. 2004;19:1055-9. PMID: 15044402 DOI: $10.1093 /$ humrep/deh216

Lessey BA, Castelbaum AJ, Sawin SW, Buck CA, Schinnar $R$, Bilker $W$, Strom BL. Aberrant integrin expression in the endometrium of women with endometriosis. J Clin Endocrinol Metab. 1994;79:643-9. PMID: 7519194 DOI: 10.1210/jcem.79.2.7519194

Lessey BA, Palomino WA, Apparao KB, Young SL, Lininger RA. Estrogen receptor-alpha (ER-alpha) and defects in uterine receptivity in women. Reprod Biol Endocrinol. 2006;4:S9. PMID: 17118173 DOI: 10.1186/1477-7827-4-S1-S9

Liu N, Zhou C, Chen Y, Zhao J. The involvement of osteopontin and $\beta 3$ integrin in implantation and endometrial receptivity in an early mouse pregnancy model. Eur J Obstet Gynecol Reprod Biol. 2013;170:171-6. PMID: 23870190 DOI: 10.1016/j.ejogrb.2013.06.019

Lu H, Yang X, Zhang Y, Lu R, Wang X. Epigenetic disorder may cause downregulation of HOXA10 in the eutopic endometrium of fertile women with endometriosis. Reprod Sci. 2013;20:78-84. PMID: 22915150 DOI: $10.1177 / 1933719112451146$
Matsuda A, Jacob A, Wu R, Zhou M, Nicastro JM, Coppa GF, Wang P. Milk fat globule-EGF factor VIII in sepsis and ischemia-reperfusion injury. Mol Med. 2011;17:126-33. PMID: 20882259 DOI: 10.2119/molmed.2010.00135

Mikolajczyk M, Wirstlein P, Skrzypczak J. The impact of leukemia inhibitory factor in uterine flushing on the reproductive potential of infertile women--a prospective study. Am J Reprod Immunol. 2007;58:65-74. PMID: 17565549 DOI: $10.1111 /$ j.1600-0897.2007.00492.x

Mirkin S, Arslan M, Churikov D, Corica A, Diaz JI, Williams $S$, Bocca S, Oehninger S. In search of candidate genes critically expressed in the human endometrium during the window of implantation. Hum Reprod. 2005;20:2104-7. PMID: 15878921 DOI: 10.1093/humrep/dei051

Oba J, Moroi Y, Nakahara T, Abe T, Hagihara A, Furue M. Expression of milk fat globule epidermal growth factorVIII may be an indicator of poor prognosis in malignant melanoma. $\mathrm{Br}$ J Dermatol. 2011;165:506-12. PMID: 21574974 DOI: 10.1111/j.1365-2133.2011.10409.x

Ordi J, Creus M, Casamitjana R, Cardesa A, Vanrell JA, Balasch J. Endometrial pinopode and alphavbeta3 integrin expression is not impaired in infertile patients with endometriosis. JAssistReprod Genet 2003;20:465-73. PMID: 14714826 DOI: 10.1023/B:JARG.0000006709.61216.6f

Schmitz C, Yu L, Bocca S, Anderson S, Cunha-Filho JS, Rhavi BS, Oehninger S. Role for the endometrial epithelial protein MFG-E8 and its receptor integrin av $\beta 3$ in human implantation: results of an in vitro trophoblast attachment study using established human cell lines. Fertil Steril. 2014;101:874-82. PMID: 24424369 DOI: $10.1016 /$ j.fertnstert.2013.12.015

Sinningen $\mathrm{K}$, Albus $\mathrm{E}$, Thiele $\mathrm{S}$, Grossklaus $\mathrm{S}$, Kurth $\mathrm{T}$, Udey MC, Chavakis T, Hofbauer LC, Rauner M. Loss of milk fat globule-epidermal growth factor 8 (MFG-E8) in mice leads to low bone mass and accelerates ovariectomyassociated bone loss by increasing osteoclastogenesis. Bone. 2015;76:107-14. PMID: 25868798 DOI: $10.1016 /$ j.bone.2015.04.003

Stewart CL, Kaspar P, Brunet LJ, Bhatt H, Gadi I, Köntgen $\mathrm{F}$, Abbondanzo SJ. Blastocyst implantation depends on maternal expression of leukaemia inhibitory factor. Nature. 1992;359:76-9. PMID: 1522892 DOI: $10.1038 / 359076 a 0$

Stubbs JD, Lekutis C, Singer KL, Bui A, Yuzuki D, Srinivasan $U$, Parry G. CDNA cloning of a mouse mammary epithelial cell surface protein reveals the existence of epidermal growth factor-like domains linked to factor VIII-like sequences. Proc Natl Acad Sci USA. 1990;87:8417-21. PMID: 2122462 DOI: 10.1073/pnas.87.21.8417

Tawfeek MA, Eid MA, Hasan AM, Mostafa M, El-Serogy HA. Assessment of leukemia inhibitory factor and glycoprotein 130 expression in endometrium and uterine flushing: a possible diagnostic tool for impaired fertility. BMC Womens Health. 2012;12:10. PMID: 22520363 DOI: $10.1186 / 1472-6874-12-10$

Taylor HS, Bagot C, Kardana A, Olive D, Arici A. HOX gene expression is altered in the endometrium of women with endometriosis. Hum Reprod. 1999;14:1328-31. PMID: 10325287 DOI: $10.1093 /$ humrep/14.5.1328 
Tei C, Maruyama T, Kuji N, Miyazaki T, Mikami M, Yoshimura Y. Reduced expression of alphavbeta3 integrin in the endometrium of unexplained infertility patients with recurrent IVF-ET failures: improvement by danazol treatment. J Assist Reprod Genet. 2003;20:13-20. PMID: 12645863 DOI: $10.1023 / A: 1021254620888$

Vogiagis D, Marsh MM, Fry RC, Salamonsen LA. Leukaemia inhibitory factor in human endometrium throughout the menstrual cycle. J Endocrinol. 1996;148:95-102. PMID: 8568476 DOI: $10.1677 /$ joe.0.1480095

von Elm E, Altman DG, Egger M, Pocock SJ, Gøtzsche PC, Vandenbroucke JP; STROBE Initiative. The Strengthening the Reporting of Observational Studies in Epidemiology (STROBE) statement: guidelines for reporting observational studies. PLoS Med. 2007;4:e296. PMID: 17941714 DOI: 10.1371/journal.pmed.0040296

Yamamoto N, Yamaguchi H, Ohmura K, Yokoyama T, Yoshifuji H, Yukawa N, Kawabata D, Fujii T, Morita S, Nagata S, Mimori T. Serum milk fat globule epidermal growth factor 8 elevation may subdivide systemic lupus erythematosus into two pathophysiologically distinct subsets. Lupus. 2014;23:386-94. PMID: 24554711 DOI: $10.1177 / 0961203314523870$
Yu L, Anderson S, Oehninger S, Bocca S. Tumor necrosis factor a up-regulates endometrial milk fat globuleepidermal growth factor 8 protein production via nuclear factor $\mathrm{KB}$ activation, resulting in cell migration of epithelial cells. Fertil Steril. 2014;101:552-9. PMID: 24262600 DOI: $10.1016 /$ j.fertnstert.2013.10.032

Zhang D, Wei J, Wang J, Liu S, Wang X, Yan Q. Difucosylated oligosaccharide Lewis $Y$ is contained within integrin av $\beta 3$ on RL95-2 cells and required for endometrial receptivity. Fertil Steril. 2011,95:1446-51. PMID: 20605574 DOI: $10.1016 /$ j.fertnstert.2010.04.036

Zhao $Y$, Gong $P$, Chen $Y$, Nwachukwu JC, Srinivasan S, Ko C, Bagchi MK, Taylor RN, Korach KS, Nettles KW, Katzenellenbogen JA, Katzenellenbogen BS. Dual suppression of estrogenic and inflammatory activities for targeting of endometriosis. Sci Transl Med. 2015b; 7:271ra9. PMID: 25609169 DOI: 10.1126/scitranslmed.3010626

Zhao JY, Ma XL, Li ZM, Deng R, Wang SM, Shen GB, Zhang J, Wang FT, Zhang BL, Wei YQ. Down-regulation of MFG-E8 by RNA interference combined with doxorubicin triggers melanoma destruction. Clin Exp Med. 2015a;15:127-35. PMID: 24619299 DOI: 10.1007/s10238-014-0277-6

Zhu LH, Sun LH, Hu YL, Jiang $Y$, Liu HY, Shen $X Y$, Jin $X Y$, Zhen $X$, Sun $H X$, Yan GJ. PCAF impairs endometrial receptivity and embryo implantation by down-regulating ß3-integrin expression via HOXA10 acetylation. J Clin Endocrinol Metab. 2013;98:4417-28. PMID: 24037888 DOI: $10.1210 /$ jc.2013-1429 